\title{
Pengaruh Rasio Liquiditas dan Solvabilitas terhadap Liquiditas pada PT. Mahkota Perkasa di Cibitung
}

\author{
Ardi Bachtiar \\ Universitas Pamulang
}

\author{
Alamat Surat \\ Email: dosen02475@unpam.ac.id
}

Article History:

Received: 10-Nopember-2020; Received in Revised: 25-Nopember-2020; Accepted: 30-Nopember-2020

\begin{abstract}
ABSTRAK
Penelitian ini bertujuan untuk mengetahui Pengaruh Rasio Liquiditas dan Solvabilitas Terhadap Profitabilitas pada PT. Mahkota Perkasa di Cibitung. Metode yang digunakan adalah explanatory research dengan sampel sebanyak 10 tahun laporan keuangan. Teknik analisis menggunakan analisis statistik dengan pengujian regresi, korelasi, determinasi dan uji hipotesis. Hasil penelitian ini Current Ratio berpengaruh signifikan terhadap Return on Asset sebesar 18,7\%, uji hipotesis diperoleh signifikansi $0,040<0,05$. Debt to Asset Ratio berpengaruh signifikan terhadap Return on Asset sebesar 57,6\%, uji hipotesis diperoleh signifikansi 0,011 < 0,05. Current Ratio dan Debt to Asset Ratio secara simultan berpengaruh signifikan terhadap Return on Asset sebesar 68,1\%, uji hipotesis diperoleh signifikansi $0,018<0,05$.
\end{abstract}

Kata kunci: Current Ratio, Debt to Asset Ratio, Return on Asset

ABSTRACT

This study aims to determine the effect of liquidity and solvency ratios on profitability at PT. Mahkota Perkasa in Cibitung. The method used is explanatory research with a sample of 10 years of financial reports. The analysis technique uses statistical analysis with regression testing, correlation, determination and hypothesis testing. The results of this study, Current Ratio has a significant effect on Return on Assets by 18.7\%, hypothesis testing obtained a significance of $0.040<0.05$. Debt to Asset Ratio has a significant effect on Return on Assets by 57.6\%, hypothesis testing obtained a significance of $0.011<0.05$. Current Ratio and Debt to Asset Ratio simultaneously have a significant effect on Return on Assets of 68.1\%, hypothesis testing obtained a significance of $0.018<0.05$.

Keywords: Current Ratio, Debt to Asset Ratio, Return on Asset

\section{PENDAHULUAN}

Dalam menghadapi persaingan bisnis perusahaan dituntut mampu menentukan kinerja usaha yang baik, sehingga perusahaan akan dapat menjamin kelangsungan hidupnya. Adapun yang menjadi tujuan dari perusahaan itu adalah untuk mencapai atau memperoleh laba yang maksimal dan optimal. Untuk mencapai tujuan tersebut maka perlu adanya perhitungan yang matang dalam menentukan struktur modal sebagai alat ukur guna menghasilkan laba yang tinggi tetapi menekan biaya - biaya operasional lain. Penilaian kinerja keungan merupakan salah satu cara yang dapat dilakukan oleh pihak manajemen agar dapat memenuhi kewajibannya terhadap para penyandang dana dan juga untuk mencapi tujuan yang telah ditetapkan pleh perusahaan. Kinerja keuangan perusahaan yang dianalisa dengan alat-alat analisa keuangan, sehingga dapat diketahui mengenai baik buruknya suatu keadaan keuangan suatu perusahaan yang mencerminkan prestasi kerja dalam periode tertentu. Hal ini penting agar sumber daya digunakan secara optimal. 
Rasio keungan merupakan salah satu alat analisa bagi keuangan untuk menilai kinerja suatu perusahaan berdasarkan perbandingan data keuangan yang terdapat pada pos (neraca, laporan laba / rugi, laporan aliran kas). Analisa rasio dapat digunakan sebagai bahan pertimbangan bagi investor dan kreditor untuk bahan pembuat keputusan atau pertimbangan tentang pencapaian perusahaan dan prospek dimasa datang. Analisa rasio keuangan menggunakan data laporan yang telah ada sebagai dasar penelitiannya. Meskipun didasarkan pada data dan kondisi masa lalu, analisa rasio keuangan. Dimaksudkan untuk menilai risiko dan peluang dimasa yang akan datang. Pengukuran dan hubungan satu pos dengan pos lain dalam laporan keuangan yang tampak dalam rasio-rasio keuangan dapat memberikan kesimpulan yang berarti dalam penentuan tingkat kesehatan suatu perusahaan.

Berikut ini data tabel peroelah CR, DAR dan ROA periode tahun 2010-2019 sebagai berikut:

Tabel Current Ratio dan Debt to Asset Ratio dan Return on Asset PT. Mahkota Perkasa Periode Tahun 2010-2019

\begin{tabular}{|l|c|c|c|}
\hline Tahun & CR $(\%)$ & DAR $(\%)$ & ROA $(\%)$ \\
\hline 2010 & 99.66 & 70.88 & 9.21 \\
\hline 2011 & 101.55 & 71.32 & 9.11 \\
\hline 2012 & 113.47 & 72.12 & 9.55 \\
\hline 2013 & 97.73 & 66.33 & 7.76 \\
\hline 2014 & 94.82 & 62.55 & 6.24 \\
\hline 2015 & 111.44 & 52.13 & 5.55 \\
\hline 2016 & 98.73 & 54.25 & 5.75 \\
\hline 2017 & 113.22 & 67.54 & 7.77 \\
\hline 2018 & 143.22 & 91.96 & 8.52 \\
\hline 2019 & 192.48 & 96.28 & 9.51 \\
\hline Rata-rata & 116.63 & 70.54 & 7.90 \\
\hline
\end{tabular}

Berdasarkan informasi pada tabel di atas, Nilai Current Ratio dapat diketahui PT. Mahkota Perkasa dari tahun 2010-2019 mengalami perkembangan yang fluktuasi dengan tingkat perkembangan rata-rata 116,63\%. Nilai Debt to Asset Ratio berdasarkan tabel di atas dapat diketahui PT. Mahkota Perkasa dari tahun 2012-2019 mengalami perkembangan yang fluktuasi. Demikian pula dengan nilai Return on Asset berdasarkan tabel di atas dapat diketahui PT. Mahkota Perkasa dari tahun 2010-2019 mengalami perkembangan yang fluktuasi dengan tingkat perkembangan rata-rata 70,54\%. Agar perusahaan dapat mencapai rentabilitas seperti yang dikehendaki, maka sebaiknya pihak perusahaan dapat mengelola harta (Asset) yang dimiliki dengan baik diantaranya adalah likuiditasnya, melalui rasio likuiditas dan rasio aktivitas. Untuk mengetahui kemampuan perusahaan dalam memenuhi kewajiban finansialnya yang harus segera terpenuhi serta untuk memperoleh gambaran tentang seberapa efektif perusahaan mengelola aktivanya perlu dilakukan analisis keuangan perusahaan khususnya mengenai likuiditas dan aktivitas Perusahaan. Analisa digunakan untuk memberikan petunjuk dan gejala-gejala serta informasi keuangan lainnya mengenai keadaan keuangan perusahaan. Berdasarkan latar belakang tersebut maka dalam pembahasan ini peneliti mengambil judul yaitu "Analisis Pengaruh Likuiditas dan Rentabilitas Terhadap Profitabilitas Pada PT. Mahkota Perkasa di Cibitung".

\subsection{Kajian Pustaka}

\section{Rasio Profitabilitas}

Yang dimaksud Rasio Profitabilitas adalah alat ukur yang digunakan untuk mengukur seberapa besar tingkat keuntungan dapat diperoleh pleh perusahaan. Dalam hal ini Rasio Profitabilitas merupakan variabel bebas (X) yang diukur dengan: net profit margin, return on equity, return on investment dan return on aset. Dan rasio likuiditas merupakan rasio yang menggambarkan 
kemampuan perusahaan dalam memenuhi kewajiban (hutang) jangka pendek) yang meliputi current rasio dan quick rasio.

\section{Kinerja Keuangan}

Menurut Jumingan (2006) kinerja keungan adalah gambaran kondisi keuangan perusahan pada suatu periode tertentu baik menyangkut aspek penghimpunan dana maupun penyaluran dana yang biasanya diukur indikator kecukupan modal, likuiditas dan profitabilitas.

\section{METODE}

Jenis penelitian yang dipakai adalah asosiatif, dimana tujuannya adalah untuk mengetahui mencari keterhubungan antara variabel independen terhadap variabel dependen. Populasi dalam penelitian ini laporan keuangan selama 10 tahun PT. Mahkota Perkasa di Cibitung. Jenis penelitian yang dipakai adalah asosiatif, dimana tujuannya adalah untuk mengetahui mencari keterhubungan antara variabel independen terhadap variabel dependen. Dalam menganalisis data digunakan uji instrumen, uji asumsi klasik, regresi, koefisien determinasi dan uji hipotesis.

\section{HASIL DAN PEMBAHASAN}

\subsection{Hasil}

\section{Analisis Deskriptif}

Pada pengujian ini digunakan untuk mengetahui skor minimum dan maksimum, mean score dan standar deviasi dari masing-masing variabel. Adapun hasilnya sebagai berikut:

Tabel 1. Hasil Analisis Descriptive Statistics

\begin{tabular}{lr|r|r|r|r} 
& \multicolumn{2}{c}{ Descriptive Statistics } & & \\
& $N$ & Minimum & Maximum & Mean & Std. Deviation \\
\hline CR (X1) & 10 & 95 & 192 & 116.63 & 30.143 \\
\hline DAR (X2) & 10 & 52 & 96 & 70.54 & 14.218 \\
\hline ROA (Y) & 10 & 6 & 10 & 7.90 & 1.557 \\
\hline Valid N (listwise) & 10 & & & & \\
\hline
\end{tabular}

Current Ratio diperoleh nilai minimum sebesar $95 \%$ dan nilai maximum $192 \%$ dengan rata-rata sebesar 116,63\% dengan standar deviasi 30,14\%. Debt to Asset Ratio diperoleh nilai minimum sebesar 52\% dan nilai maximum 96\% dengan mean score sebesar 70,54\% dengan standar deviasi 14,21\%. Return on Asset diperoleh varians minimum sebesar $6 \%$ dan nilai maximum $10 \%$ dengan rata-rata sebesar $7,90 \%$ dengan standar deviasi $1,55 \%$.

\section{Analisis Verifikatif.}

Pada analisis ini dimaksudkan untuk mengetahui pengaruh variabel independen terhadap variabel dependen. Adapun hasil pengujian sebagai berikut:

\section{Analisis Regresi Linier Berganda}

Uji regresi ini dimaksudkan untuk mengetahui perubahan variabel dependen jika variabel independen mengalami perubahan. Adapun hasil pengujiannya sebagai berikut:

Tabel 2. Hasil Pengujian Regresi Liner Berganda

\section{Coefficients $^{\mathrm{a}}$}

Unstandardized

Coefficients

Model

B

Std. Error

\section{Standardized}

Coefficients

Beta

Sig.

\begin{tabular}{l|l|l|l}
1.873 & 1.681 & 1.115 & .302 \\
\hline
\end{tabular}




\begin{tabular}{|l|r|r|r|r|r}
\hline CR $(X 1)$ & -.029 & .019 & -.562 & -1.520 & .172 \\
\hline DAR $(X 2)$ & .133 & .040 & 1.218 & 3.295 & .013 \\
\hline
\end{tabular}

a. Dependent Variable: ROA (Y)

Berdasarkan hasil pengujian pada tabel di atas, diperoleh persamaan regresi $\mathrm{Y}=1,873$ 0,029X1 + 0,133X2. Dari persamaan tersebut dijelaskan sebagai berikut:

a. Konstanta sebesar 1,873 diartikan jika Current Ratio dan Debt to Asset Ratio tidak ada, maka telah terdapat nilai Return on Asset sebesar 1,873 point.

b. Koefisien regresi Current Ratio sebesar -0,029, angka ini positif artinya setiap ada peningkatan Current Ratio sebesar -0,029 maka Return on Asset juga akan mengalami penurunan sebesar 0,029 point.

c. Koefisien regresi Debt to Asset Ratio sebesar 0,133, angka ini positif artinya setiap ada peningkatan Debt to Asset Ratio sebesar 0,133 maka Return on Asset juga akan mengalami peningkatan sebesar 0,133 point.

\section{Analisis Koefisien Korelasi}

Analisis koefisien korelasi dimaksudkan untuk mengetahui tingkt kekuatan hubungan dari variabel independen terhadap variabel dependen baik secara parsial maupun simultan. Adapun hasil pengujian sebagai berikut:

Tabel 3. Hasil Pengujian Koefisien Korelasi Current Ratio Terhadap Return on Asset.

\section{Correlations $^{\text {a }}$}

\begin{tabular}{llr|r} 
& & Current Ratio (X1) & Return on Asset (Y) \\
\hline CR (X1) & Pearson Correlation & 1 & .433 \\
\cline { 2 - 4 } & Sig. (2-tailed) & & .211 \\
\hline ROA (Y) & Pearson Correlation & .433 & 1 \\
\cline { 2 - 4 } & Sig. (2-tailed) & .211 & \\
\hline
\end{tabular}

Berdasarkan hasil pengujian diperoleh nilai korelasi sebesar 0,433 artinya Current Ratio memiliki hubungan yang sedang terhadap Return on Asset.

Tabel 4. Hasil Pengujian Koefisien Korelasi Debt to Asset Ratio Terhadap Return on Asset. Correlations $^{\text {b }}$

Debt to Asset Ratio

\begin{tabular}{llr|r} 
& & $\begin{array}{r}\text { Debt to Asset Ratio } \\
(\mathrm{X} 2)\end{array}$ & Return on Asset (Y) \\
\hline DAR (X2) & Pearson Correlation & 1 & $.759^{*}$ \\
\cline { 2 - 4 } & Sig. (2-tailed) & & .011 \\
\hline ROA (Y) & Pearson Correlation & $.759^{*}$ & 1 \\
\cline { 2 - 4 } & Sig. (2-tailed) & .011 & \\
\hline
\end{tabular}

Berdasarkan hasil pengujian diperoleh nilai korelasi sebesar 0,759 artinya Debt to Asset Ratio memiliki hubungan yang sangat kuat terhadap Return on Asset.

Tabel 5. Hasil Pengujian Koefisien Korelasi Current Ratio dan Debt to Asset Ratio secara simultan Terhadap Return on Asset.

\section{Model Summary}

\begin{tabular}{lr|r|r|r|} 
Model & $\mathrm{R}$ & R Square & Adjusted R Square & Std. Error of the Estimate \\
\hline 1 & $.826^{\mathrm{a}}$ & .681 & .590 & .996 \\
\hline
\end{tabular}

a. Predictors: (Constant), DAR (X2), CR (X1) 
Berdasarkan hasil pengujian diperoleh nilai korelasi sebesar 0,826 artinya Current Ratio dan Debt to Asset Ratio secara simultan memiliki hubungan yang kuat terhadap Return on Asset.

\section{Analisis Koefisien Determinasi}

Analisis koefisien determinasi dimaksudkan untuk mengetahui besarnya persentase pengaruh dari variabel independen terhadap variabel dependen baik secara parsial maupun simultan. Adapun hasil pengujian sebagai berikut:

Tabel 6. Hasil Pengujian Koefisien Determinasi Current Ratio Terhadap Return on Asset.

\section{Model Summary}

\begin{tabular}{|c|c|c|c|c|}
\hline Model & $\mathrm{R}$ & R Square & $\begin{array}{l}\text { Adjusted R } \\
\text { Square }\end{array}$ & $\begin{array}{l}\text { Std. Error of the } \\
\text { Estimate }\end{array}$ \\
\hline 1 & $.433^{\mathrm{a}}$ & .187 & .086 & 1.489 \\
\hline
\end{tabular}

a. Predictors: (Constant), CR (X1)

Berdasarkan hasil pengujian diperoleh nilai determinasi sebesar 0,187 artinya Current Ratio memiliki kontribusi pengaruh sebesar 18,7\% terhadap Return on Asset.

Tabel 7. Hasil Pengujian Koefisien Determinasi Debt to Asset Ratio Terhadap Return on Asset.

\begin{tabular}{|c|c|c|c|c|}
\hline \multicolumn{5}{|c|}{ Model Summary } \\
\hline Model & $\mathrm{R}$ & R Square & $\begin{array}{l}\text { Adjusted R } \\
\text { Square }\end{array}$ & $\begin{array}{l}\text { Std. Error of the } \\
\text { Estimate }\end{array}$ \\
\hline 1 & $.759^{\mathrm{a}}$ & .576 & .523 & 1.075 \\
\hline
\end{tabular}

a. Predictors: (Constant), DAR (X2)

Berdasarkan hasil pengujian diperoleh nilai determinasi sebesar 0,576 artinya Debt to Asset Ratio memiliki kontribusi pengaruh sebesar 57,6\% terhadap Return on Asset.

Tabel 8. Hasil Pengujian Koefisien Determinasi Current Ratio dan Debt to Asset Ratio Terhadap Return on Asset.

Model Summary

\begin{tabular}{|c|c|c|c|c|}
\hline & & 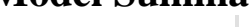 & & \\
\hline Model & $\mathrm{R}$ & R Square & $\begin{array}{l}\text { Adjusted R } \\
\text { Square }\end{array}$ & $\begin{array}{l}\text { Std. Error of the } \\
\text { Estimate }\end{array}$ \\
\hline 1 & $.826^{\mathrm{a}}$ & .681 & .590 & .996 \\
\hline
\end{tabular}

a. Predictors: (Constant), DAR (X2), CR (X1)

Berdasarkan hasil pengujian diperoleh nilai determinasi sebesar 0,681 artinya Current Ratio dan Debt to Asset Ratio secara simultan memiliki kontribusi pengaruh sebesar 68,1\% terhadap Return on Asset, sedangkan sisanya sebesar $31,9 \%$ dipengaruhi faktor lain.

\section{Uji Hipotesis}

\section{Uji hipotesis Parsial (Uji t)}

Pengujian hipotesis dengan uji t digunakan untuk mengetahui hipotesis parsial mana yang diterima.

Tabel 9. Hasil Uji Hipotesis Current Ratio Terhadap Return on Asset.

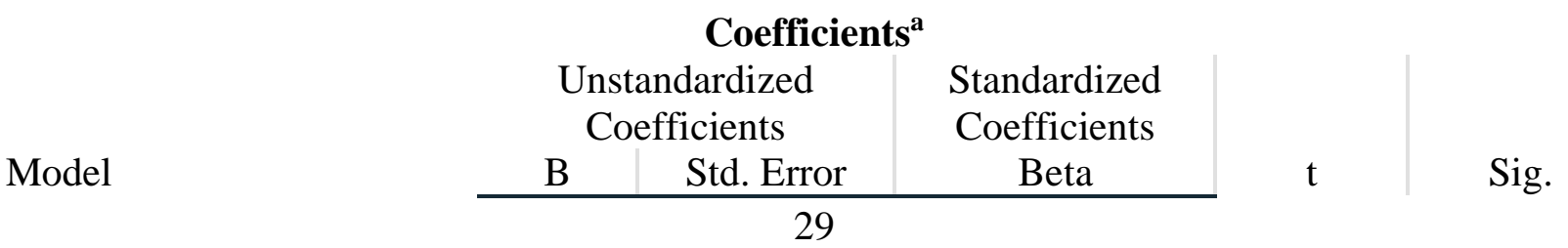




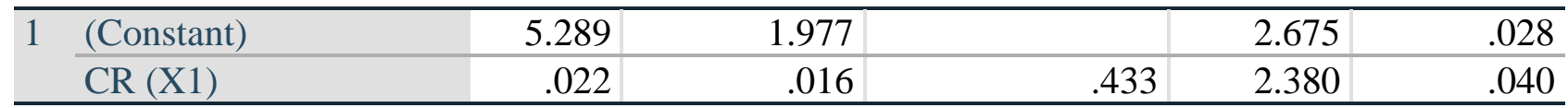

a. Dependent Variable: ROA (Y)

Berdasarkan hasil pengujian pada tabel di atas, diperoleh nilai thitung $>\mathrm{t}$ tabel atau $(2,380>2,365)$, dengan demikian hipotesis terdapat pengaruh yang signifikan atara Current Ratio terhadap Return on Asset diterima.

Tabel 10. Hasil Uji Hipotesis Debt to Asset Ratio Terhadap Return on Asset.

\begin{tabular}{|c|c|c|c|c|c|c|}
\hline \multirow{3}{*}{\multicolumn{2}{|c|}{ Model }} & \multicolumn{2}{|c|}{ Coefficients $^{\mathbf{a}}$} & \multirow[b]{2}{*}{$\begin{array}{l}\text { Standardized } \\
\text { Coefficients }\end{array}$} & \multirow[b]{3}{*}{$\mathrm{t}$} & \multirow[b]{3}{*}{ Sig. } \\
\hline & & \multicolumn{2}{|c|}{$\begin{array}{l}\text { Unstandardized } \\
\text { Coefficients }\end{array}$} & & & \\
\hline & & $\mathrm{B}$ & Std. Error & Beta & & \\
\hline$\overline{1}$ & (Constant) & 2.033 & 1.810 & & 1.124 & .294 \\
\hline & DAR (X2) & .083 & .025 & .759 & 3.299 & .011 \\
\hline
\end{tabular}

a. Dependent Variable: ROA (Y)

Berdasarkan hasil pengujian pada tabel di atas, diperoleh nilai $\mathrm{t}$ hitung $>\mathrm{t}$ tabel atau $(3,299>2,365)$, dengan demikian terdapat pengaruh yang signifikan atara Debt to Asset Ratio terhadap Return on Asset diterima.

\section{Uji Hipotesis Simultan (Uji F)}

Pengujian hipotesis dengan uji $\mathrm{F}$ digunakan untuk mengetahui hipotesis simultan yang mana yang diterima.

Tabel 11. Hasil Uji Hipotesis Current Ratio dan Debt to Asset Ratio Terhadap Return on Asset.

\begin{tabular}{|c|c|c|c|c|c|c|}
\hline \multicolumn{7}{|c|}{ ANOVA $^{\mathrm{a}}$} \\
\hline \multicolumn{2}{|c|}{ Model } & Sum of Squares & df & Mean Square & $\mathrm{F}$ & Sig. \\
\hline 1 & Regression & 14.867 & 2 & 7.434 & 7.488 & $.018^{\mathrm{b}}$ \\
\hline & Residual & 6.949 & 7 & .993 & & \\
\hline & Total & 21.816 & 9 & & & \\
\hline
\end{tabular}

Berdasarkan hasil pengujian pada tabel di atas, diperoleh nilai $\mathrm{F}$ hitung $>\mathrm{F}$ tabel atau $(7,488>$ 4,350), dengan demikian terdapat pengaruh yang signifikan atara Current Ratio dan Debt to Asset Ratio terhadap Return on Asset diterima.

\subsection{Pembahasan}

\section{Pengaruh Current Ratio Terhadap Return on Asset}

Current Ratio tidak berpengaruh signifikan terhadap Return on Asset dengan korelasi sebesar 0,433 atau memiliki hubungan yang sedang dengan kontribusi pengaruh sebesar $18,7 \%$. Pengujian hipotesis diperoleh nilai $\mathrm{t}$ hitung $>\mathrm{t}$ tabel atau $(2,380>2,365)$. Dengan demikian terdapat berpengaruh yang signifikan antara Current Ratio terhadap Return on Asset.

\section{Pengaruh Debt to Asset Ratio Terhadap Return on Asset}

Debt to Asset Ratio berpengaruh signifikan terhadap Return on Asset dengan korelasi sebesar 0,759 atau memiliki hubungan yang kuat dengan kontribusi pengaruh sebesar 57,6\%. Pengujian hipotesis diperoleh nilai $\mathrm{t}$ hitung $>\mathrm{t}$ tabel atau (3,299 > 2,365). Dengan demikian terdapat berpengaruh yang signifikan antara Debt to Asset Ratio terhadap Return on Asset.. 


\section{Pengaruh Current Ratio dan Debt to Asset Ratio Terhadap Return on Asset}

Current Ratio dan Debt to Asset Ratio berpengaruh signifikan terhadap Return on Asset dengan diperoleh persamaan regresi $\mathrm{Y}=1,873-0,029 \mathrm{X} 1+0,133 \mathrm{X} 2$, nilai korelasi sebesar 0,826 atau memiliki hubungan yang kuat dengan kontribusi pengaruh sebesar 68,1\% sedangkan sisanya sebesar $31,9 \%$ dipengaruhi faktor lain. Pengujian hipotesis diperoleh nilai $\mathrm{F}$ hitung $>\mathrm{F}$ tabel atau $(7,488>$ 4,350). Dengan demikian terdapat berpengaruh yang signifikan antara Current Ratio dan Debt to Asset Ratio terhadap Return on Asset.

\section{KESIMPULAN}

\subsection{Kesimpulan}

a. Current Ratio berpengaruh signifikan terhadap Return on Asset dengan kontribusi pengaruh sebesar $18,7 \%$. Uji hipotesis diperoleh nilai t hitung $>\mathrm{t}$ tabel atau $(2,380>2,365)$.

b. Debt to Asset Ratio berpengaruh signifikan terhadap Return on Asset dengan kontribusi pengaruh sebesar 57,6\%. Uji hipotesis diperoleh nilai t hitung > t tabel atau $(3,299>2,365)$.

c. Current Ratio dan Debt to Asset Ratio berpengaruh signifikan terhadap Return on Asset dengan kontribusi pengaruh sebesar $68,1 \%$ sedangkan sisanya sebesar $31,9 \%$ dipengaruhi faktor lain. Uji hipotesis diperoleh nilai $\mathrm{F}$ hitung $>\mathrm{F}$ tabel atau $(7,488>4,350)$.

\subsection{Saran}

a. Perusahaan harus mengoptimalkan semua sumber daya perusahaan untuk mencapai profit yang lebih tinggi

b. Perusahaan harus mencari alternatif lain guna menarik investor agar modal bertambah.

c. Kinerja perusahaan dapat memperkuat nilai dbet to equity ratio agar nilai equitas meningkat

\section{DAFTAR PUSTAKA}

Agus Harjito \& Martono, (2010) “Manajemen Keuangan” Yogyakarta: Penerbit Ekonisia.

Agus Sartono. (2010). "Manajemen Keuangan Toeri dan Aplikasi”, Edisi keempat, Yogyakarta: Penerbit BPFE.

Algifari. (2015). “Analisis Regresi untuk Bisnis dan Ekonomi”. Yogyakarta: BPFE.

Arikunto, Suharsimi (2014). "Prosedur Penelitian Suatu Pendekatan Praktek". Jakarta: Rineka Cipta.

Bambang Riyanto, (2011). “Dasar-dasar Pembelanjaan Perusahaan”. Edisi ke empat, BPFE Yogyakarta.

Fahmi, Irham (2012), “Pengantar Manajemen Keuangan” Cetakan pertama. Bandung: Penerbit Alfabeta.

Imam Ghozali (2017). “Aplikasi Analisis Multivariate Dengan Program SPSS”. Edisi Kelima. Semarang: Badan Penerbit Undip.

Istijanto (2014) “Riset Sumber Daya Manusia”. Jakarta: PT. Gramedia Pustaka

Jasmani, J. (2018). Pengaruh Kinerja Keuangan Terhadap Harga Saham (Analisis Pada Perusahaan Property dan Real Estate Yang Go Public di Bursa Efek Indonesia. Jurnal Akuntansi Indonesia, 12(2).

Jasmani, J. (2019). The Effect of Liquidity and Working Capital Turnover on Profitability at PT. Sumber Cipta Multiniaga, South Jakarta. PINISI Discretion Review, 3(1), 29-38.

Kasmir (2008), “Analisi Laporan keuangan”, penerbit raja grafindo persada, Jakarta.

Kasmir. (2012) “Pengantar Manajemen Keuangan”, Edisi Pertama, Cetakan kedua, Jakarta: Prenada Media. 
Kharis, Ismu Fadli (2011). “Studi Mengenai Impulse Buying dalam Penjualan Online”. Semarang : Skripsi Universitas Diponegoro

Martono dan Agus Harjito, (2011). “Manajemen Keuangan”, Jakarta: Penerbit Ekonisia..

Munawir (2010), “Analisis Laporan Keuangan”, Edisi Ke Empat, Penerbit Liberty, Yogyakarta.

Ni Putu Yuria Mendra (2016), "Pengaruh Rasio Keuangan Terhadap Price Earing Ratio Pada Perusahaan Manufaktur yang terdaftar di Bursa Efek Indonesia Tahun 2012-2014" Universitas Mahasaraswati Denpasar,

Nofiana, L., \& Sunarsi, D. (2020). The Influence of Inventory Round Ratio and Activities Round Ratio of Profitability (ROI). JASa (Jurnal Akuntansi, Audit dan Sistem Informasi Akuntansi), 4(1), 95-103.

Santoso, Singgih (2015). “Menguasai Statistik Multivariat”. Jakarta: PT Elex Media Komputindo.

Sartono, “Manajemen Keuangan Aplikasi Dan Teori”, Edisi Keempat, BPFE, Yogyakarta, 2008.

Sawir, (2003). “Analisis Kinerja Keuangan dan Perencanaan Keuangan Perusahaan”, Cetakan ketiga, Jakarta: Penerbit PT. Gramedia Pustaka Utama.

Sudjana (2014) “Metode Statistika”, Bandung: Tarsido.

Sugiyarso, G. dan F. Winarni, "Manajemen Keuangan (Pemahaman Laporan Keuangan, Pengelolaan Aktiva, Kewajiban dan Modal serta Pengukuran

Sugiyono (2017), "Metode Penelitian Administrasi : dilengkapi dengan Metode $R \& D$ ”. Bandung: Alfabeta.

Sunarsi, D. (2018). Pengembangan Sumber Daya Manusia Strategik \& Karakterisrik Sistem Pendukungnya : Sebuah Tinjauan. Jurnal Ilmiah MEA (Manajemen, Ekonomi, \& Akuntansi), 2(3), 178 - 194.

Sunarsi, D. (2020). The Analysis of The Work Environmental and Organizational Cultural Impact on The Performance and Implication of The Work Satisfaction. Jurnal Ilmiah Ilmu Administrasi Publik, 9(2), 237-246.

Sunarsi, D., \& Baharuddin, A. (2019). The Effect of Service Quality and Price Accuracy on Consumer Confidence and Implications for Sales Increase. PINISI Discretion Review, 3(2), 101110.Ilmu Administrasi Publik, 9(2), 237-246.

Sunaryo (2011) Pengaruh Current Ratio, Debt To Equity Ratio, Dan Devidend Pay Out Ratio Terhadap Price Earning Ratio Pada Kelompok Perusahaan Manufaktur Yang Terdaftar di Bursa Efek Indonesia Binus Business Review Vol. 2 No. 2: 866-873.

Susanti, N., Latifa, I., \& Sunarsi, D. (2020). The Effects of Profitability, Leverage, and Liquidity on Financial Distress on Retail Companies Listed on Indonesian Stock Exchange. Jurnal Ilmiah Ilmu Administrasi Publik, 10(1), 45-52.

Wijoyo, H., Handoko, A. L., Santamoko, R., \& Sunarsi, D. (2020). Strategy Model for Character Education Through Digital Media for Courses and Training Participants. E-Prosiding Pascasarjana Universitas Negeri Gorontalo, 1-8.

Wijoyo, H. (2020). Analisis Pengendalian Internal Dalam Pemberian Kredit Pada PT Bank Perkreditan Rakyat (BPR) Indomitra Mandiri. TIN: Terapan Informatika Nusantara, 1(4), 157-162.

Wijoyo, H. (2018). Analisis Pengakuan Pendapatan dan Beban Kontrak Konstruksi Pada PT. Wahana Tata Riau. Jurnal Ilmu Komputer dan Bisnis, 9(2), 2034-2043. 